\title{
FEUERBACH: NOTAS SOBRE ANTROPOLOGIA E POLÍTICA
}

\author{
FEUERBACH: NOTES ON ANTHROPOLOGY AND POLITICS
}

Antônio Adriano de Meneses Bittencourt*

\section{RESUMO}

Neste artigo, discutiremos o pensamento antropológico de Ludwig Feuerbach na dimensão da política, enfatizando que sua crítica é, acima de tudo, um manifesto contra a exploração do homem pelo homem. Avaliaremos também as condições de possibilidade do exercício da liberdade no contexto político. De acordo com isso, serão postos em evidência os riscos de um projeto político que se queira impor a todos, uma vez que, segundo o filósofo, estando a liberdade ligada à individualidade, só o homem determinado, concreto e particular e, de um modo geral, só um povo tomado em sua singularidade estética, espiritual, moral e racional estaria em condições de avaliar o tipo de legislação e governo que melhor lhe serve. Em articulação às ideias do filósofo alemão, evocamos a crítica de José Carlos Mariátegui (18941930) ao processo de colonização e posteriormente, de abertura política no Peru como exemplo do histórico e intricado dilema entre política e liberdade.

PALAVRAS-CHAVE: Feuerbach; antropologia; liberdade; política; Mariátegui.

\section{ABSTRACT}

In this article, we will discuss Ludwig Feuerbach's anthropological thinking in its political aspect, emphasizing that his criticism is, above all, a manifesto against the exploitation of man by man. We will also assess the possibility conditions for the exercise of freedom in the political context. According to that, we evidence the risks of a political project which wants to impose on everyone, once that, according to Feuerbach, freedom, connected to individuality, only the determined, concrete and particular man and, on a general way, only a people taken in his aesthetic, spiritual, moral and rational singularity would be in evaluation conditions legislation and government that better serves you. In articulation to the ideas of the german philosopher, we evoke the criticism of José Carlos Mariátegui (1894-1930) to the colonization process and then, of political opening in Peru as an example of the historical and intricated dilemma between politics and freedom.

KEYWORDS: Feuerbach; anthropology; freedom; politics; Mariátegui.

A obra de Feuerbach pode, a princípio, revelar muito mais ao pesquisador contemporâneo do que ele possa prever. Estamos certos disso, pois, lendo-a, podemos ter a sensação de estarmos diante de um pensador que reflete com sobriedade e determinação os problemas fundamentais da humanidade, situando-se ao lado dos chamados filósofos

\footnotetext{
* Mestre em filosofia Universidade Federal do Ceará. E-mail: adriano468@ yahoo.com.br.
} 
"póstumos", pois suas ideias cruzam os séculos posteriores. Dada a sua obscuridade e assistematicidade, bem como certo ostracismo de parte da historiografia filosófica oficial, seus escritos foram pouco tomados a sério antes que fosse deles feito uma imagem vulgar e, inevitavelmente, caricata. Até aí, podemos dizer que não se trata de alguma novidade, sendo frequente a adoção de tal prática entre os filósofos, dos quais Feuerbach também não figurará como "exceção à regra".

À parte isso, o propósito que nos motivara escrever este artigo está, no entanto, em outro elemento. Refere-se à particularidade de seu pensamento antropológico em articulação a alguns excertos extraídos de seu pensamento político. Desde já, salientamos tratar-se de um assunto mais amplo, devendo, nos limites deste texto, ter sua apreciação apenas enquanto um esforço particular de nossa parte com vistas a descortinar novos rumos nas pesquisas sobre o filósofo. Dito isso, passemos à tarefa que nos colocamos.

Chama-nos a atenção, em primeiro lugar, o que Feuerbach compreende por homem integral. A descrição que seguirá será por meio de um exemplo concreto sob a assinatura dos pressupostos de sua noção geral de homem, tal como o filósofo a desenvolve em A essência do cristianismo, publicada em 1841, a saber, formado por três qualidades ou forças essenciais: afetos (coração), vontade e razão ${ }^{1}$. Nessa obra, Feuerbach investiga a religião cristã e conclui reduzindo-a aos "poderes" da essência do homem, sendo, desse modo, a religião um fenômeno humano, e a teologia uma "antropologia invertida". As discussões, na obra, se concentram em revelar o objeto da religião, Deus, como um ser construído pela subjetividade, revelando, assim, o prenúncio de uma era que porá em discussão o papel da religião em relação ao Estado.

Um pouco mais tarde, em Princípios da filosofia do futuro, de 1843, Feuerbach “esboçará” um projeto filosófico em que propõe a superação da filosofia de seu tempo. Outrora conduzindo os homens a refletirem sobre os limites da religião, agora, o filósofo discute os limites da filosofia. Feuerbach almeja, assim, a liberdade em todas as frentes. Mas o que é liberdade? O que significa ser livre? Para ele, só o homem é verdadeiramente livre, pois,

\footnotetext{
${ }^{1}$ Pouco se alude ao fato de Feuerbach ter caracterizado o ser humano de forma trinitária. Sabe-se que a constituição tríplice está na história do pensamento de diferentes formas, por exemplo, na religião, pelo Cristianismo (Pai, Filho, Espírito Santo); a explicação das partes da alma na filosofia platônica (logistikon, thymoeides, epithymetikon); no ocultismo ou no misticismo, em relação às partes da alma segundo a cabala (nefesh, ruah e neshamah) etc. Um interessante estudo sobre os diferentes significados do número três associado a esses empregos encontramos no trabalho do ocultista francês Papus em seu Traité élémentaire de science occulte, de 1888, (com tradução para o português). Permanece, no entanto, incógnito se Feuerbach copia essa forma de classificação de algumas dessas tradições. Contudo, não nos parece como um todo estranho se considerarmos que sua filosofia pretende tornar concreto o que fora tomado como místico ou abstrato, "convertendo", assim, cada uma dessas forças ou disposições em partes constituintes da essência material do homem, portanto, físicas e naturais.
} 
diferentemente dos demais animais, os quais são conduzidos por uma relação mais imediata com a natureza, o primeiro vai além da pura determinação, portanto, podendo experienciar o mundo de uma forma mais rica e universal, recolhendo em seu interior todo o universo ${ }^{2}$. Convém, assim, antes de considerarmos sua explicação acerca do homem integral, avaliar o que o filósofo nos diz sobre a diferença entre aquele e os demais animais.

O homem de nenhum modo se distingue do animal só pelo pensamento. Pelo contrário, o seu ser total é que o distingue do animal. Sem dúvida, aquele que não pensa não é homem algum; não é porque o pensar seja a causa do ser humano, mas unicamente por que é uma consequência e uma propriedade necessária do mesmo ser humano. Por conseguinte, não precisamos aqui de sair do domínio da sensibilidade para reconhecer no homem um ser superior aos animais. O homem não é um ser particular como o animal, mas um ser universal, por conseguinte, não é um ser limitado e cativo, mas um ser ilimitado e livre; com efeito, a universalidade, a ilimitação e a liberdade são inseparáveis. E esta liberdade também não reside numa faculdade particular, na vontade, da mesma maneira que esta universalidade não se situa numa disposição particular da faculdade de pensar, na razão — esta liberdade, esta universalidade estende-se ao seu ser total. Sem dúvida, os sentidos animais são mais agudos do que os humanos, mas apenas em relação a coisas determinadas, necessariamente conexas com as necessidades do animal, e são mais agudos justamente por causa dessa determinação, dessa restrição exclusiva a algo de determinado. $\mathrm{O}$ homem não tem o faro de um cão de caça, de um corvo; mas apenas porque o seu olfacto pode abranger todas as espécies de odores, pelo que é um sentido livre e indiferente a respeito de odores particulares. Mas onde um sentido se eleva acima dos limites da particularidade e da sua vinculação à necessidade, eleva-se a uma significação e dignidade autónomas, teóricas: sentido universal é o entendimento, sensibilidade universal é espiritualidade. Mesmo os sentidos mais baixos, o olfacto e o gosto, se elevam no homem a actos espirituais e científicos. ${ }^{3}$ (FEUERBACH, 2008, p. 70-71, grifo nosso).

Por meio da consciência de si, resultado da interação entre o eu e o tu, desperta-se no homem o sentimento do universal, podendo expandir "seus horizontes", traçar planos sempre novos para si, reconhecer seus direitos, lutar por eles. A consciência é seu "trunfo" ante os poderes que se lançam a subjugá-lo, a deitar-lhe as mãos no intuito de oprimi-lo. Os animais, ainda que lhes reconheçamos as façanhas e argutas disposições, deixam-se determinar pela natureza. Posto isso, atentemos agora ao que Feuerbach compreende como homem em sentido pleno.

\footnotetext{
2 “O homem, um microcosmo", famosa citação atribuída a Demócrito.

${ }^{3}$ É importante ressaltar que a noção de superioridade aludida na citação, ainda que expresse simplesmente a razão como uma qualidade específica do homem em relação aos demais seres, posteriormente irá se diluir em uma concepção de natureza horizontalizada, advogando, Feuerbach, contra o suposto direito do ser humano sobre a natureza em detrimento dos outros animais, o que coloca Feuerbach, em nossa ótica, na vanguarda dos desdobramentos que culminarão mais tarde nas diversas correntes do ecologismo.
} 
A arte, a religião, a filosofia ou a ciência são apenas as manifestações ou revelações do ser humano verdadeiro. Homem perfeito e verdadeiro é apenas quem possui o sentido estético ou artístico, religioso ou moral, filosófico ou científico — homem em geral somente é aquele que nada de essencialmente humano exclui de si mesmo. Homo sum, humani nihil a me alienum puto - esta frase, tomada na sua significação mais universal e mais elevada, é a divisa do novo filósofo. (FEUERBACH, 2008, p. 72, grifo nosso).

Assim, o homem integral, isto é, considerado enquanto tal, é aquele em quem nada lhe é subtraído na qualidade de homem, na expressão íntima de sua essência. Na comparação com os demais animais, "sobram-lhe" atributos, por meio dos quais, permite-se a passagem do simples ao complexo, do isolado ao integrado, do uno ao múltiplo. Trouxemos essa passagem, no entanto, para fazer a seguinte consideração: se o homem verdadeiro é, assim, aquele que não deixa de fora o que lhe é próprio, em consonância ao que é expresso pela frase em latim (extraída de Terêncio) que acompanha o texto citado logo acima, devemos compreender, assim, entre os demais aspectos constituintes da essência total do homem, a dimensão religiosa como igualmente dignitária ao lado das outras duas (estética, científica).

Por que nos chama atenção, em particular, a religiosidade em detrimento das outras facetas do humano (científica, filosófica, etc.)? Por uma razão simples: Feuerbach é conhecido como um crítico "mordaz" da religião. De fato, suas obras atestam uma desmistificação do sagrado, revelando, concomitantemente, uma postura radical em favor de uma recusa do prelado eclesiástico e de seus abusos frente à sociedade. Contudo, essa postura não encerra a opinião geral do filósofo acerca da religião. Em verdade, a religião nos limites da individualidade, da escolha pessoal, não está em questão. Feuerbach compreende a religião como propiciadora de uma relação obscura do homem consigo, onde se desenvolve, subjetivamente, uma caracterização específica no tocante à figura divina, mas há um motivo maior por trás dessa crítica que se nos descortina ao observarmos com cuidado suas reflexões. Observemos o seguinte relato:

\footnotetext{
Interesso-me acima de tudo, e sempre me interessou, iluminar a obscura essência da religião com a luz da razão, para que finalmente os homens parem de ser explorados, para que deixem de ser joguetes de todos aqueles poderes inimigos da humanidade que, como sempre, servem-se até hoje da nebulosidade da religião para a opressão do homem. (FEUERBACH, 2009, p. 35).
}

Portanto, distingue-se em sua crítica uma meta, um objetivo, a saber, libertar o homem do jugo opressor daqueles que se valem do discurso religioso para realizar seus desígnios sobre a vontade dos demais. Vemos, dessa forma, uma atitude, por assim dizer, política por parte do 
autor, que não se conforma com os abusos cometidos pelo uso arbitrário a que está sujeita a religião. Mas estaria apenas a religião condenada a uma tal ressalva? Não estaria, pois, a filosofia e a teoria, mesmo sob as mais belas aspirações, sujeitas a incorrer em expedientes de semelhantes abusos e opressões? No tocante à política, Feuerbach não se dedicará a análises aprofundadas, conservando, para seus detratores, a imagem de um pensador pouco consciente da situação real em que vivem os homens. De fato, o filósofo não tomará partido no que toca a um tipo específico de governo, como lemos no trecho seguinte:

\begin{abstract}
Já Aristóteles diz em sua Política [...] que não só devemos conhecer a melhor legislação, mas também saber para quais homens ela convém, porque até a mais excelente não convém a todos. Por isso, quando se me constrói, sob o ponto de vista histórico [...] a monarquia constitucional [...] como única forma de governo que nos convém [...] eu concordo plenamente. Mas quando se me demonstra, sem se tomar em conta espaço e tempo [...] a monarquia como a única forma de governo racional, então, eu protesto. ( FEUERBACH, 2009, p. 374, grifo nosso)
\end{abstract}

Claramente, a maior parte das críticas de Feuerbach se dirige ao Estado cristão, que oprime aqueles que enxergam suas contradições e lutam pelo fim de seu domínio arbitrário, mas pode aqui ser aplicada a qualquer governo que utilize a retórica autoritária para fins de controle e punição de seus dissidentes. Porém, em ilação ao texto citado logo acima, cabe-nos alguns questionamentos: o que dizer das formas de governo que, ainda que assentadas no espaço e no tempo, portanto, na empiria, irrompem com ganas de obter a todo esforço o domínio sem recusar mesmo o uso da violência? Seria suficiente para a política estar ela radicada na historicidade? Não teriam os homens também uma história? Não estaria a história também subordinada à subjetividade? A isso, responderemos mais adiante.

Voltando ao tema da religião, ainda que esta constitua um perigoso e abstruso meio de dispor das liberdades, segundo Feuerbach, não decorre que ela seja abolida ${ }^{4}$. A liberdade para tomar a si ou a natureza de forma mistificada é fruto também do homem integral pelo qual advoga. Nem mesmo a filosofia e a ciência escapam de devaneios e fantasias porquanto encerram atividades do espírito. Que se ponha, pois, nos termos de uma compreensão solidária consigo a crítica do filósofo: Feuerbach é ciente de que a imaginação e a fantasia fazem parte

\footnotetext{
4 "Mas eu teria caído no delírio, na loucura, se quisesse acabar com a religião no sentido em que meus inimigos me acusam. Eu não destruo a religião, os elementos e bases subjetivas, isto é, humanas, da religião, nem o sentimento e a fantasia, nem o ímpeto de objetivar e personificar o próprio íntimo, o que já existe na própria natureza do idioma e da afeição, nem a necessidade de humanizar a Natureza, de torná-la objeto de uma visão poética e filosófico-religiosa numa maneira correspondente a sua essência como se nos tornou conhecida através da ciência natural." (FEUERBACH, 2009, p. 205).
} 
da vida humana, porém, na política, podem mais facilmente assumir o espectro do arbitrário quando ali se arvoram. Ao que indica, cabia a Feuerbach antes de assumir um lugar entre os teóricos da política de seu tempo, propondo caminhos e soluções práticas nesse campo, denunciar os vestígios de autoridade fundada no subjetivismo, mesmo que se circunscrevesse sob os auspícios de uma política laica ou ateia. Em uma outra passagem, lemos: "Em sentido prático é o individualismo um socialismo, não, porém, no sentido francês que é um socialismo que tira a liberdade ou a individualidade, o que dá na mesma, sendo essa última apenas uma expressão mais abstrata." (FEUERBACH, 2009, p. 394).

A liberdade, assim, pode estar comprometida em qualquer forma de governo, pois sempre haverá uma tentativa de suprimi-la em nome de uma abstração que se suponha o bem de "todos". Chamamos, no entanto, a atenção para as palavras de Feuerbach ao comparar liberdade com individualidade. Liberdade e individualidade são, assim, expressões que diferem apenas enquanto substantivos, mas não em essência. Ambas atestam a condição fundamental para que se possa chamar alguém verdadeiramente homem. Temos, aqui, uma pista que conflagra, ainda que sutilmente, uma chave de interpretação pouco afeita à "caricatura" dele. Seria Feuerbach, tomando sua antropologia, conhecedor de dissonâncias irreconciliáveis entre os homens no campo político? Se essa hipótese se mostrar válida, em que "norte" se situaria seu pensamento político? Claro nos parece, com base em sua concepção de liberdade, tomá-lo como precursor de ideias políticas nos termos que o socialismo científico (ateu, laico), na forma do bolchevismo, representou na instauração do socialismo real, quando este esteve sob a tutela de Stálin, da Inquisição na Idade Média. O que dizer, então, da eugenia hitlerista e dos crimes cometidos contra o ser humano, limpezas étnicas, trabalhos forçados e todas as formas de massificação humana no capitalismo neoliberal fundadas em algum propósito "maior" pelos seus idealizadores?

O elemento utópico que outrora afirmamos ficar de fora da política por lhe ser prejudicial é, contudo, presente nos homens, pois, acompanhando a discussão sobre a liberdade aqui, refere-se à sua expressão singular, assim, ao âmbito da individualidade. Porém, aplicada ao discurso político, a utopia pode facilmente assumir sua "sombra distópica", tal como a história nos mostrou em relação às diversas formas de imposição política que retirara ao homem seu direito de ser homem . Dessa forma, se a política é "feita" pelos homens, e considerando-

\footnotetext{
${ }^{5} \mathrm{O}$ impactante livro do escritor judeu italiano Primo Levi, É isto um homem? (1988), narrando os pormenores da brutalidade nazista por ele presenciada quando esteve prisioneiro em Auschwitz, nos dá um triste, porém, necessário exemplo disso.
} 
se a liberdade como fundamento distintivo destes, parece que nos encontramos em uma situação paradoxal na qual o homem deve negar-se para ser livre em sentido político.

A noção de liberdade como sinônimo de individualidade torna-se problemática na política porque transgride toda regra geral, toda "pretensa" universalidade impositiva sobre o modo determinado que assinala a subjetividade dos povos, não podendo, esta, ser extenuada por qualquer critério que lhe seja externo. Assim, podemos responder aos questionamentos mais acima da seguinte forma: na política, é necessário que se concilie a história com a individualidade, com as formas de ser e pensar no tempo e no espaço, estes, concreções experimentadas pelo modo distintivo de vida de cada povo. Mas falta uma consideração a ser feita. A liberdade, por si, não é suficiente. Tomada como simples palavra, desraigada das condições de existência, é supérflua. O homem quer ser, além de livre, feliz, pois como ser livre sem ser feliz? Mais: quem pode nos prover a felicidade? A isso, o filósofo responde: "A felicidade varia de acordo com o país, as pessoas, o tipo de homem." (FEUERBACH, 1997, p. 28). Ser feliz, portanto, é uma condição também única e particular de cada povo, exigindo que qualquer argumento que envolva a garantia de liberdade deve incluir a felicidade em restrita observância aos costumes daquele. Desconsiderando a felicidade como parte indissociável da liberdade, o homem sucumbe à bestialidade, assim, enfraquece-se o que de mais íntimo e humano há em si.

\footnotetext{
Cada impulso insatisfeito, cada desejo não satisfeito, cada desconforto, cada sentimento de privação, cada perda é uma deficiência ou uma negação, que desperta a perturbação do [...] instinto de felicidade, inato em cada ser vivo e senciente [...]. "Vontade sem liberdade é uma palavra vazia", diz Hegel. Mas uma palavra vazia e sem sentido é antes de tudo liberdade sem felicidade [...] Onde o mal não é mais percebido como um mal, nem a opressão dos despotismos, de qualquer tipo, como opressão, também a liberdade do mal e a opressão não é mais percebida e desejada como felicidade; mas quando um ser cessa de desejar a felicidade, cessa de desejar em sentido absoluto, cai à mercê da estupidez. (FEUERBACH, 1997, p. 13-14, grifo nosso).
}

Como visto, Feuerbach está cônscio das dificuldades surgidas ao se tomar a liberdade de uma forma meramente abstrata, desraigada das condições concretas que definem as características de um povo, pois, estando ela em estreita ligação à felicidade, seria um total arbítrio exigir ao homem ser feliz de um modo diferente em que ele possa experienciar esse sentimento, ademais, que fosse livre sem oferecer as condições que lhe assegurem ser feliz. Essa citação é mais uma forma de vermos como o pensamento de Feuerbach partilha das 
opiniões do Estagirita, agora, ressaltando o papel da felicidade como responsabilidade da política, ainda que em Aristóteles o tema se articule por meio do estudo das virtudes.

De um modo geral, nem mesmo a república pode ser tomada como uma palavra que em si garanta o bem-estar de todos, pois a aspiração republicana pode ser meramente teórica, mas não de coração (FEUERBACH, 2008, p. 30). Desse modo, compreendemos a crítica de Feuerbach como uma denúncia muito mais ampla do que a convencional imagem de "crítico da religião" a que lhe foi outorgada pela história da filosofia, uma vez que seus argumentos são um panegírico à liberdade, uma denúncia radical dos abusos da teoria sobre a vida; da forçada atribuição de normas e leis que, sob qualquer pretexto, despreze aquilo que a experiência dos homens consinta em sua práxis como o melhor e mais adequado.

Desse modo, se tomarmos a felicidade como apanágio da liberdade, qualquer forma de governo que a preconize não pode ser subtraída por uma outra, ainda que se outorgue melhor, se naquela residir todo o modo de vida de um povo, um equívoco mostrado na prática pelos países do bloco socialista no século vinte, que, para ficar apenas no que diz respeito à religiosidade, ao invés de instituir uma proposta que favorecesse o sentimento ecumênico, tratando como assunto privativo (LÊNIN, 1905), a massacrou e oprimiu, exterminando alguns de seus representantes, forçando a natureza humana a amoldar-se aos desígnios do programa de governo.

Vê-se a razão pela qual Feuerbach se distanciou das ideias políticas de seu tempo. Sua filosofia admoestava dos perigos a que estão sujeitos os homens que se colocam à disposição das ideias e ao poder de outrem. Sua crítica à religião não pode ser confundida como uma postura arbitrária por parte do filósofo que visa expurgar do homem o seu direito de pensar e de viver conforme o modo particular de experienciar o mundo ${ }^{6}$. Sua tarefa é trazer à luz os elementos subjetivos que determinam a fé, o que não pode ser confundido com uma atitude político-ideológica que se autorize a determinar aquilo que os homens devem crer. É o que lemos na seguinte passagem da Ética:

Como em minha Essência da religião minha tarefa não é demonstrar que não existe deus, e certamente que nem mesmo que não exista um, então aqui minha tarefa não é demonstrar que o homem não tem a chamada liberdade de vontade, mas certamente que nem mesmo a tenha. Como lá eu apenas investigo as razões que determinam a fé do homem em Deus, então aqui minha tarefa, ou pelo menos minha principal tarefa,

\footnotetext{
6 “As coisas «externas» não são o único objecto dos sentidos. O homem só é dado a si mesmo através dos sentidos - ele é para si mesmo objecto enquanto objecto dos sentidos. A identidade de sujeito e objecto, apenas pensamento abstracto na autoconsciência, é verdade e realidade efectiva somente na intuição sensível que o homem tem do homem" (FEUERBACH, 2008, p. 60).
} 
foi apenas traçar e representar as razões que determinam o homem ser livre. (FEUERBACH, 1997, p. 94-95, tradução nossa). ${ }^{7}$

Parece-nos, assim, ter Feuerbach uma postura muito mais madura e consciente do que o relato de Engels nos sugere ${ }^{8}$. Deus e liberdade são conceitos, porém estão em estrita relação com a individualidade, assim, determinados pelo modo em que o homem se relaciona com o mundo. Portanto, não é retirar coisa alguma do ser humano para que passe a ser "novo", mas, diferentemente, pô-lo em evidência em totalidade, aclarando-lhe aquilo que retira seu direito de pensar e agir em conformidade com o que julga melhor para si, seja na religião ou na política, para que se combata a exploração do homem pelo homem, para que não se justifiquem os abusos e injustiças a preço de uma ideia que se queira incontestável.

Desse modo, só pode haver a liberdade se o homem for tomado em sua condição singular e, por isso, plural, múltipla, pelo acordo conjunto dessas forças originais que, segundo Feuerbach, definem as potências básicas da natureza humana, que se eleva e enriquece quanto menos os homens são privados de serem homens. Ora, seriam os desenvolvimentos do iluminismo e do positivismo favoráveis a um tal entendimento? O que se viu foi justamente a "entronização" de uma única faceta do humano, a saber, a razão, uma crença que só os filósofos (aqui, entre aqueles tomados por Feuerbach enquanto afeitos a uma imagem abstrata de homem) podiam crer, uma razão desvinculada do sentir, da vivência prática, longe do coração do homem real. O perigo, portanto, da racionalidade transformar-se em um algoz no que toca a liberdade é latente, dado que ela, a razão, por si, também pode ser dada aos delírios, como Feuerbach escreve a respeito da filosofia de Hegel. Por isso, o termo "razão", na obra de Feuerbach, encarna-se na vivência prática dos seres, devendo, ela, estar também sujeita à história e não sujeitá-la.

\footnotetext{
7 “Come nella mia Essenza delia religione il mio compito non è dimostrare che non esiste alcun dio, e certo neppure che ne esiste uno, cosi qui il mio compito non è quello di dimostrare che l'uomo non ha la cosiddetta liberta dei volere, ma certo nemmeno che ce l'ha. Come là io indago soltanto le ragioni che determinano l'uomo alia fede in Dio, cosi qui il mio compito, o almeno il mio compito principale, era soltanto quello di rintracciare e rappresentare i motivi che determinano l'uomo a ritenersi libero."

${ }^{8}$ Engels acusa Feuerbach de não querer eliminar a religião. De acordo com ele: "Onde se revela o verdadeiro idealismo de Feuerbach é em sua filosofia da religião e em sua ética. Feuerbach não pretende, de forma alguma, suprimir a religião, o que deseja é completá-la. A própria filosofia deve converter-se em religião". (ENGELS, 1988, p. 12). Concorda com nossa interpretação, apoiados em textos do próprio Feuerbach, que não há a pretensão de sua parte em destruir a religião. Contudo, a afirmação de que ele teria o interesse em completá-la, se compreendemos essa expressão usada por Engels no sentido de "elevá-la" transformando- $a$ em filosofia, fazendo, assim, da filosofia uma espécie de religião para o homem, não podemos encontrar uma justificativa para tal, pois, a nós, parece evidente que quando Feuerbach emprega essa "transmutação", o faz menos como um projeto filosófico definido do que como um anseio "poético", pois reconhece a força que a religião, cuja natureza intrinsecamente ligada ao coração do homem, leva o último aos mais altos sacrifícios e martírios em nome de Deus, aspirando que assim também se passasse na ciência e na filosofia.
} 
Com base nisso, chegamos à seguinte questão: se a política se define pela individualidade, pela particularidade e esta deve ser tal que favoreça a felicidade de seu povo, que características deveria possuir o governo para que promovesse o bem-estar geral? Sabemos que Feuerbach era francamente desfavorável à ideia de uma sociedade governada pela religião, mas se a racionalidade, pretenso pressuposto para o discurso que se quer combater toda forma de arbítrio, também pode ser usada para fins que encarcerem o homem (acaso não podemos supor que o socialismo francês não seria embasado na razão?), que fundamento deve, então, distinguir o bom de um mau governante? Abre-se aqui uma questão bastante delicada e que devemos, apenas a título de ilustração, mencionar o seguinte caso.

Sabemos como se deu a colonização dos povos americanos. A total aculturação forçada pelos ditames das coroas portuguesa e espanhola levou à morte milhares de nativos do novo continente, infestando-o de doenças, assassinatos, roubos e toda sorte de ameaça à integridade das populações indígenas, alvos de monstruosa violência em nome de poder e riquezas que os colonos poderiam daquelas terras extrair.

Um dos mais significativos estudos sobre esse período da história da América encontrase na obra de José Carlos Mariátegui, pensador de verve marxiana cujo trabalho, entre outros temas, ressalta as diferenças dos povos nativos da América (sua cultura, política, economia etc.) em relação ao modelo político-econômico do ocidente europeu. Para Mariátegui, um dos mais danosos efeitos da colonização fora a total desintegração da identidade do nativo por meio das leis da república que, ao contrário de garantir o direito de todos, manteve um sistema regido por caudilhos empurrando a população indígena ao desespero e à exclusão.

Em paralelo, de acordo com esse autor, a noção de progresso nos termos da república peruana, oriunda do jacobinismo (que, de modo pejorativo, nada mais significa que uma forma demagógico-abstrata de defender a liberdade dos povos) manteria intocado o problema do nativo peruano, uma vez que nem mesmo o voto poderia servir de qualquer tipo de garantia para a melhoria de sua situação. Desse modo, abandonados à própria sorte, a ruína de toda uma tradição de experiências que formaram a identidade da população indígena fora exterminada em prol de um modelo de organização político-social estranho à sua formação, sob a bandeira da emancipação. Nem mesmo o voto os livraria desse destino. De acordo com Mariátegui ((Regionalismo y centralismo, p. 5),

Las masas rurales, las comunidades indígenas, en todo caso, se mantendrían extrañas al sufragio y a sus resultados. Y, en consecuencia, aunque no fuera sino porque los ausentes no tienen nunca razón -"les absents ont toujour tort"- los organismos y los 
poderes que se crearían "electivamente", pero sin su voto, no podrían ni sabrían hacerles nunca justicia. ${ }^{9}$

Segundo o autor, a república é o maior inimigo do indígena, porque não pode compreendê-lo. A população indígena possui sua essência ligada à terra e à comunidade. $L a$ tierra ha sido siempre toda la alegría del índio (MARIÁTEGUI, Sobre el problema indígena, p. 2). São povos que formaram sua identidade no acúmulo de práticas e vivências na própria natureza e de modo coletivo. Se a individualidade é apenas um termo abstrato para liberdade como nos diz Feuerbach, e sendo a liberdade, no exemplo supracitado, uma garantia dada por um instrumento (voto), estranho aos costumes nativos, logo, em articulação à "regra" que nem a mais excelente das legislações convém a todos, considera-se que, na visão do filósofo, um tal exemplo jamais poderia estar de acordo com uma concepção razoável de política, dado que o que é tomado como melhor ou superior (a república) é imposta em flagrante arbítrio contra a natureza das convenções que regem e determinam a singularidade dos colonizados.

E Mariátegui sai em defesa dos povos indígenas do Peru justamente por isso: O homem do Ocidente, afeito ao individualismo, à abstração, ao universal, está em contraposição ao indígena, coletivista, sensorial e regionalista. Dois pensamentos completamente distintos, dois modelos incapazes de se comunicarem. Excetuando os casos em que a superstição causa danos irreversíveis à integridade humana, nada há que se condene na prática entre ambas as formas. Feuerbach bem o sabia quando em suas Preleções sobre a essência da religião, contrapondo as religiões da natureza às religiões do espírito, ressalta que embora as primeiras não fossem livres de superstições, como a religião em geral, elas conduzem o homem a tomar como sagrada a própria natureza e, assim, reconhecer sua necessidade e importância para a vida. Como não deixar de ver certa beleza poética em um povo que eleva ao nível de uma divindade uma árvore ou um lago? Quisera a humanidade pudesse hoje ter se elevado a uma tal saúde espiritual!

A liberdade política deve, assim, ser articulada com a individualidade histórica para que o homem não venha a ser subtraído em seu modo particular de existir, isto é, para que não seja condenado a um viver com base em um modelo de organização estranhado por ele. $\mathrm{O}$ bem e o mal têm sua expressão bem definida no homem, e Feuerbach parecia bem sabê-lo, se precavendo em tomar parte da euforia política de seu tempo.

\footnotetext{
${ }^{9}$ Optamos por manter as citações em espanhol sem traduzi-las por razão de maior familiaridade com nossa língua materna.
} 


\section{CONCLUSÃO}

Abordamos aqui o pensamento de Feuerbach sob uma perspectiva bastante particular, discorrendo sobre o tema da liberdade nos limites de sua antropologia filosófica, dando passagem para algumas incursões em questões políticas que acreditamos tocarem diretamente o tema. Quisemos neste artigo apresentar sua filosofia como abstraída de um projeto político definido, pois o tema da liberdade transcende a qualquer matéria particular, sendo, portanto, a questão da emancipação humana, antes, um compromisso firme com o primado da soberania e da autodeterminação.

Em consonância a isso, mostramos por meio do particular exemplo da colonização e, posteriormente, da república peruana que se constitui dois casos distintos de violência (monarquista e republicana) ao modo de vida dos povos nativos, tal como esse fato nos é relatado pela obra de Mariátegui, forçando-nos a observar por meio de um exemplo real os problemas da aplicação de um modelo de liberdade em sentido político que intente o universal, ainda que embasado em preceitos que se pretendam "elevar a natureza dos homens", pois há sempre o risco de se fazer impor uma forma de governo que não esteja de acordo com a organização e costumes de um povo, argumento que Feuerbach retoma de Aristóteles para ilustrar sua concepção de política. Para Mariátegui, a república, saudada na modernidade como modelo pour l'excellence de emancipação política, resultou no despacho de uma massa de homens desorientados, cuja violência e genocídio que sua memória sofrera séculos antes tornaram em migalhas o lastro que os reconduziria ao sentido pleno da vida.

Neste texto, ao tratarmos do tema da liberdade, avaliamos que, no que toca à política, para Feuerbach, é indiferente o emprego de qualquer forma de governo, pois o filósofo está mais interessado nos elementos subjetivos da dominação e exploração do homem, combatendo tanto os extremismos da razão como da fé, porquanto compreende não existir razões absolutas e universais que concedam, por si, o direito a dispor da liberdade alheia, dada que essa descansa no particular. Portanto, em extrema concordância com seu pensamento, não são as ideias que devem guiar o homem a um destino saudável, mas, ao contrário, são os homens que devem guiar as ideias, abdicando delas sempre que sentirem que estão sendo tiranizados. 


\section{REFERÊNCIAS}

ENGELS, F. Ludwig Feuerbach e o fim da filosofia clássica alemã. 1988. Disponível em http://www.escolapcdob.org.br/file.php/1/materiais/pagina_inicial/Biblioteca/54_ENGELS_L udwig_Feuerbach.pdf. Acesso em: 10 abr. 2021.

FEUERBACH, L. Ética e Felicità. Milano: Guerini e Associati, 1997.

FEUERBACH, L. Preleções sobre a essência da religião. Tradução de José da Silva Brandão. Petrópolis, RJ: Vozes, 2009.

FEUERBACH, L. Princípios da filosofia do futuro. Tradução de Artur Morão. Covilhã: LusoSofia Press, 2008. Disponível em:

http://www.lusosofia.net/textos/feuerbach_ludwig_principios_filosofia_futuro.pdf. Acesso em: 06 set. 2020.

LÊNIN, V. I. O socialismo e a religião. 1905. Disponível em

https://www.marxists.org/portugues/lenin/1905/12/03.htm. Acesso em: 17 abr. 2021.

LEVI, P. É isto um homem? Rio de Janeiro: Rocco, 1988.

MARIÁTEGUI, José Carlos. Regionalismo Y Centralismo. Disponível em https://www.archivochile.com/Ideas_Autores/html/mariategui_jc.html. Acesso em 12 mar. 2021.

MARIÁTEGUI, José Carlos. Sobre el problema indigena. Disponível em https://biblioteca.org.ar/. Acesso em 12 mar. 2021. 